Dunaetz, D. R. (2010). Long distance managerial intervention in overseas conflicts: Helping missionaries reframe conflict along multiple dimensions. Missiology, 38, 281-294.

\title{
Long Distance Managerial Intervention in Overseas Conflicts Helping Missionaries Reframe Conflict along Multiple Dimensions
}

\author{
David R. Dunaetz
}

\begin{abstract}
[Abstract] Effective ways of conflict management must be found for missionaries when no trusted mediator in the region is available. Home office management or leaders in other regions can intervene through context rich media, such as the telephone and video conferencing, to provide help. Intervention through context poor media, such as email, is much less likely to succeed. Effective managerial intervention involving interaction with each party can lead to reframing the conflict into an opportunity to cooperate and find mutually beneficial solutions. The manager can present information, ask questions, and help the parties see that resolution is possible by addressing key issues such as the relative importance of the consequences, the potential win-win nature of the solution, each party's sense of victimization, and the certainty of continued interaction in the relationship.
\end{abstract}

Conflict intervention and management is one of the most disagreeable yet common tasks of managers in any organization (Pruitt and Kim 2004:11-13; Rahim 2001:7-14; Weingart and Jehn 2000). Regardless of how much one may dislike conflict, it is a normal part of life. When conflicts are not managed or dealt with properly, the consequences can be devastating. The need for conflict management and intervention is often underestimated, but it is nonetheless crucial, especially in organizations that are driven more by vision and convictions than by profit, such as is the case for mission organizations. Missionaries are motivated by their values, and when a conflict arises that appears to threaten their values, the conflict can quickly escalate and spiral into a relational catastrophe, undermining the work of the mission and often leading to missionary attrition (Hay, Lim, Blocher, Ketelaar, and Hay 2007; Schneider, Goldstein, and Smith 1995). When a conflict occurs between missionaries, managers either in the home office or located in another region are often the first to hear about the problem or are expected to intervene quickly in such a situation, regardless of how unprepared they might feel to provide constructive guidance in conflicts.

The Inevitability of Overseas Conflicts The responsibility of managers to intervene, as well as the difficulty of intervening effectively, is all the more important when the organization's employees are living overseas or in another region, separated from the management of the sending organization to whom they report. A handful of missionaries may be working together in a country far from their sending agency or in a region other than where their management is located. These missionaries may have little or no training in conflict management or resolution. However, they may need to work very closely with one another since they are, to some degree, outsiders in their target country and most likely have not completely mastered the language and culture as well as an insider would. Similarly, they are probably dependent upon one another for achieving their goals if they are in a team situation where they have a common organizational vision, especially a vision that is difficult to achieve. They probably have high expectations of what they hope to accomplish and are 
counting on one another to get there. If there is not a common organizational vision, mutual dependence is less likely; there may only be a unilateral dependence of one party upon the other because of the imposed mission structure.

Whenever one person is dependent upon another (whether it be a mutual dependence or a unilateral dependence), there is a risk of conflict becoming competitive and destructive (Wilmot and Hocker 2001:43-45). If only one person is dependent upon the other, this person can easily become frustrated if the other does not provide the support desired. If both parties are dependent upon each other to accomplish their goals, any deviation in behavior that does not lead to accomplishing the other party's goals can lead to frustration. Conflict becomes inevitable, and even normal, in such situations. The way the conflict is handled, which often depends on the manager in the home country or another region, will determine the conflict's outcome. Conflicts can have positive results, producing a solution to the problem that is superior to what either party would have proposed by itself. On the other hand, conflicts can have negative consequences, resulting in inferior solutions, damaged relationships, and even withdrawal from the organization (Deutsch 1973; Johnson, Johnson, and Tjosvold 2000). The outcome of a severe conflict will depend, to a large degree, on how well mission leadership intervenes.

\section{Resistance to Third Party Intervention} Although third party intervention (such as mediation) is, in general, quite effective (Carnevale and Pruitt 1992; Pruitt and Carnevale 1993), the parties involved in conflict may resist it, especially in overseas conflict that occurs far away from the sending organization. In missions contexts, resistance to mediation may be due to the missionary's high commitment to his or her values. If a party sees its position as the morally correct position, intervention by a third party may be perceived as encouraging compromise or a change of position that would be morally difficult to accept. The intervention might be viewed as promoting moral compromise or a threat to biblical authority.

Third party intervention might also be resisted because of a lack of trust in local mediators who could help missionaries in conflict. A local potential mediator might not understand the cultural point of view of the disputants (who are foreigners from his or her perspective) or the missionaries' ethnocentrism (which can significantly increase during times of stress) might make them resistant to entrusting part of their destiny to someone outside of their own culture. The distance from the home country might make it impossible for their manager to travel to the field, making a face-to-face intervention impossible. Other co-workers within the organization in the host country might be potential mediators, but they may fear to intervene because of the relational risks involved or because of lack of training. Furthermore, the more powerful party often resists mediation because the involvement of a mediator leads to a loss of the advantage that comes from a difference in power (Wilmot and Hocker 2001:274-277).

All of these factors make it all the more difficult for mission leaders to intervene in overseas conflicts among missionaries. But these factors do not make such intervention any less necessary. If the manager aspires to the biblical model of a leader as a servant (Matt. 20:25-27) and a shepherd (1 Pet. 5:1-3), such intervention is absolutely essential. Understanding the basic dynamics of conflict and distance communication will enable managers to be better prepared to implement a conflict intervention strategy. 
This article will propose such a strategy after presenting a discussion of the underlying theory.

\section{Theoretical Considerations}

Conflict, on the simplest level, may be said to exist "whenever incompatible activities occur.... An action that is incompatible with another action prevents, obstructs, interferes, injures, or in some way makes the latter less likely or less effective" (Deutsch 1973:10). Yet a conflict may also occur when an incompatibility does not actually exist, but is perceived to exist. In addition, perceived incompatible activities must create a problem; if neither party is bothered or reacts to such incompatibilities, one cannot say a conflict exists. A more complete definition of conflict is "an expressed struggle between at least two interdependent parties who perceive incompatible goals, scarce resources, [or] interference from others in achieving their goals" (Wilmot and Hocker 2001:41).

The Dual Concern Model of Conflict Behavior

Responses to conflict can be measured along two dimensions: 1) concern for one's own interests and 2) concern for other's interests (Phil. 2:4; Blake and Mouton 1964; Pruitt and Kim 2004:40-47; Rahim 2001:35-62). These two dimensions are closely related to other similar dimensions: orientation towards the task (concern for one's own interests) and orientation towards the relationship (concern for other's interests). Concern for one's own interests and concern for other's interests can each be considered high or low, resulting in the following four conflict styles:

\begin{tabular}{|c|c|c|}
\hline $\begin{array}{l}\text { Concern for } \\
\text { One's Own } \\
\text { Interests } \\
\text { (Task } \\
\text { Orientation) }\end{array}$ & $\begin{array}{l}\text { Concern for } \\
\text { Other's } \\
\text { Interests } \\
\text { (Relationship } \\
\text { Orientation) }\end{array}$ & $\begin{array}{c}\text { Conflict } \\
\text { Style }\end{array}$ \\
\hline Low & Low & Avoidance \\
\hline Low & High & Accommodation \\
\hline High & Low & Competition \\
\hline High & High & Cooperation \\
\hline
\end{tabular}

In general, the combination of a high concern for one's own interests and a high concern for the other's interests creates an atmosphere conducive to problem solving. This style, cooperation, takes into account the interests of both parties and most likely leads to a win-win situation, responding to the desires and concerns of all involved and providing solutions to complex problems, superior to what other styles produce (Fisher, Ury, and Patton 1991). Other styles are appropriate under various circumstances (e.g., avoidance when both parties agree that a difference is not worth the time to discuss it, or accommodation when the relationship is far more important than the issue to one, but not both, of the parties), but in complex situations of some importance, cooperation is the conflict style that is most likely to produce superior solutions to problems and results that are satisfying for both parties.

All individuals have a preferred conflict style that comes most naturally to them by the time they are adults. For some people, cooperation is more natural, others are by nature more competitive, and so on. This natural tendency can be measured by various instruments (Kilmann and Thomas 1977; Kraybill 2005; Rahim 2001:35-62) and is somewhat determined by one's personality traits (Antonioni 1998; Sandy, Boardman, and Deutsch 2000). For example, people who are low in the trait of agreeableness tend to be more 
competitive. People who are high in the trait of agreeableness tend toward accommodation. People who worry a lot and get nervous easily tend toward avoidance (Antonioni 1998). However, people may also choose to use a specific conflict style according to the circumstance (Lewicki, Saunders, and Barry 2006:22-69). An individual may choose a certain style because of a desire to maximize outcomes or because of his or her values and beliefs concerning the process by which a conflict should be resolved. If one believes that each party's interests and concerns are legitimate, he or she will tend to choose a cooperative style. If one believes that the most powerful person should dominate (due to organizational hierarchy, expertise in the subject matter, or relationships with others, for example), a competitive or accommodating style would be chosen in accordance with one's evaluation of his or her power relative to the other person. If such a person believes he or she is more powerful, he or she will take a competitive style; if the person sees himself or herself in a position of less power, he or she will choose an accommodating style. Others might believe that a Christian should always be accommodating and act accordingly, ignoring their own desires or what they believe is the best thing to do in the situation.

When an important conflict exists, it is essential that both parties take a cooperative approach to maximize the likelihood of a constructive (win-win) resolution. However, if one party takes a cooperative approach, the other party may take a competitive approach, potentially resulting in a less satisfying or even destructive (win-lose) resolution. To prevent this from happening, the party that desires a competitive approach must reframe the conflict to see the advantages of resolving the conflict through cooperative efforts and come to a constructive solution (Deutsch 2000). This, as we will see, is where third party interventions on the part of mission leaders can be extremely useful.

Reframing

Frames are to conflicts as culture is to human civilization. Each party in a conflict has beliefs, values, and expectations that shape its view of the conflict. A conflict frame includes how a conflict is defined, what the critical issues are, and what strategy is appropriate to resolve the conflict. Yet frames can change, either because a party receives new information or has some other motivation to see the conflict in a different light. "Reframing occurs through challenging the way that a party conceives of an issue, or through demonstrating that a current frame is ineffectual" (Putnam and Holmer 1992:140). For example, reframing is likely to occur when the two parties begin to understand each other's perspective. However, reframing is not likely to occur when negative emotions are running high or when the parties are not open to new information. In such situations, the intervention of a trusted, outside third party would be useful. A manager's intervention to calm the situation and create an atmosphere where the parties are more open to new information can help the parties reframe the conflict so that a mutually acceptable solution can be found. For example, when two missionaries are in a conflict where at least one takes a competitive stance, it would be helpful for a manager to intervene and help the competitive employee reframe the conflict as an opportunity for cooperation that can lead to a satisfactory solution for both parties. The manager may do this by discerning and focusing upon the interests of both parties, especially in light of the overarching mission of the organization (Fisher et al. 1991). 
One way that reframing occurs is through double-loop learning (Argyris 1993). Single-loop learning is the normal process by which individual members of organizations modify their actions and practices to get results that are closer to the organization's goals; by trial and error or by experimenting with new ideas, individuals become more effective. In double-loop learning, the members of the organization question the assumptions and values that led to the current actions and practices of the organization. They then consider the possibility of other assumptions or seek more consistent values in order to propose other actions or practices. In conflictual situations, learning about the assumptions and values that led to the conflict allows the conflict to be reframed in more manageable ways.

Media Richness Theory

All communication requires a medium. In face to face communication, words and gestures are verbally communicated directly to the other person through audible and visual signals. The telephone may serve as a medium to transmit audible signals, and email may serve as a medium to transmit written words. Some mediums are "richer" and some are "leaner" in media richness theory (Daft and Lengel 1984, 1986; Dennis and Kinney 1998), which indicates that rich media should be chosen in more difficult and ambiguous communication situations, and lean media should be chosen in easier and unambiguous communication situations.

One aspect of the richness of a given medium can be determined by considering to what degree three main aspects of the message can be transmitted using that medium: 1) the verbal message itself (the words that are written or spoken), 2) the vocal cues (the audible messages not transmitted in words, such as inflection, sighs, gasps, and accents), and 3) nonverbal messages (e.g., gestures, body position, touch). Face-to-face communication is the richest form of communication because verbal messages, vocal cues, and nonverbal messages are all transmitted with minimal loss. Written letters and emails are the leanest form of communication because only the verbal message is communicated. Conversation by telephone is an intermediately rich form of communication; it allows for the transmission of verbal messages and vocal cues, but not nonverbal messages. Video conferencing is even more rich than telephone (when there are no technical problems), but less rich than physical presence (due to screen resolution limitations, static interference, and the limited band width of data transmission). Another aspect of media richness

is the degree to which communication feedback is possible and timely. In face-toface communication, one party can often see immediately from the facial expression of the other party that something is not understood or has been misinterpreted. This is not the case in email communication; when an email communicates a message unintended by its author, this miscommunication may only be discovered days later, or possibly never. Although no medium guarantees that the intended message will be understood, the opportunity for immediate feedback increases the likelihood that the message will be properly understood.

Communication tasks vary in difficulty of the information processing that is required. Media richness theory states that the more information processing is required, the richer the communication medium should be. Difficult communication tasks include equivocal or ambiguous communication when there are multiple possible interpretations of the information being communicated. Such a situation requires context rich media in 
order to communicate the most information possible with minimal loss. In addition, a context rich medium will enable immediate feedback to make sure the communication has been understood. For example, if a missionary discovers some ambiguous information about some unusual behavior on the part of another missionary, it would most likely be best to discuss this in a face-to-face conversation rather than by email. Difficult communication tasks typically involve an element of emotion (Argyris 1993) that is often poorly communicated in writing but can be more accurately handled in richer contexts, where immediate feedback is available.

An easy communication task involves information that is not ambiguous and is not emotional. It can therefore be communicated with a context lean media. For example, the time, date, and flight number of a colleague who is arriving at the airport can easily be communicated by email; there is no need to have a face-toface meeting to communicate this information.

In mission organizations, it is not always possible to have face-to-face meetings, due to the distance between parties. Normally, in very difficult situations, such as those involving conflict, a face-to-face meeting involving the parties and a mediator would be preferred (typically the mediator would meet individually with each party before bringing them together), but this is often not possible. King and Xia (1997) found that a conversation by telephone is universally preferred to email for resolving a conflict in such a case. The high emotional content which often occurs in conflict requires the richest communication medium possible. It requires a medium that allows immediate feedback to ensure accurate communication of messages. The chosen media must also be able to transmit the emotional details of the message, which allow the parties to detect attempts to repair the relationship or subtle signs that the other party feels threatened. If such information is lost, conflict resolution is unlikely.

Other studies of email have shown that there tends to be little trust when two parties negotiate by email, compared to richer forms of communication (Naquin and Paulson 2003). Negotiation is an attempt to resolve conflict through dialogue (rather than fighting or avoidance), which can often lead to a win-win solution, especially when the two parties trust each other. The lack of trust in email communication is especially notable when the relationship between the two parties is strained or weak (Paulson and Naquin 2004). Without trust, it is highly unlikely that a mutually acceptable solution will be found in difficult situations (Dirks and Ferrin 2001; Simons and Peterson 2000).

A further problem with email, compared to richer communication media, is the asynchronous nature of the messages sent and received, characterized by delays in responses, crossed messages, and messages that are lost or disregarded (Montoya-Weiss, Massey, and Song 2001). The difficulty of coordinating a dialogue carried on by email discourages feedback to confirm understanding. In some cases, a recipient of a misinterpreted message will not even attempt to give or receive feedback because of the delays involved. Furthermore, it is often the norm that many topics will be discussed in the same email, rather than discussing one topic at a time as would occur in richer communication media. This can result in information overload and the missing of important details. The emotionally provocative issues tend to become the primary focus of the received message. These issues then become the topic of the next round of communication and the less provocative 
material is overshadowed, although it might be just as, or even more, important. This less emotional content may form the basis for cooperation and for understanding the other person's perspective, but it is easily ignored when emotions are running high.

\section{A Conflict Intervention Strategy Greenhalgh (1986) proposes} several dimensions of conflict frames that influence the degree to which a conflict is difficult or easy to resolve:

\begin{tabular}{|c|c|c|}
\hline Dimension & $\begin{array}{l}\text { Difficult to } \\
\text { Resolve } \\
\text { Frame }\end{array}$ & $\begin{array}{l}\text { Easier to } \\
\text { Resolve } \\
\text { Frame }\end{array}$ \\
\hline $\begin{array}{l}1 . \\
\text { Involvement } \\
\text { of a third } \\
\text { party }\end{array}$ & $\begin{array}{l}\text { No neutral } \\
\text { third party } \\
\text { available. }\end{array}$ & $\begin{array}{l}\text { Trusted, } \\
\text { powerful, } \\
\text { and neutral } \\
\text { third power } \\
\text { ready to get } \\
\text { involved. }\end{array}$ \\
\hline $\begin{array}{l}\text { 2. The nature } \\
\text { of the issue } \\
\text { causing the } \\
\text { conflict }\end{array}$ & $\begin{array}{l}\text { A moral } \\
\text { issue }\end{array}$ & $\begin{array}{l}\text { A non-moral } \\
\text { issue }\end{array}$ \\
\hline $\begin{array}{l}3 . \\
\text { Anticipated } \\
\text { consequence } \\
\text { S }\end{array}$ & Major & Minor \\
\hline $\begin{array}{l}4 . \\
\text { Anticipated } \\
\text { resolution }\end{array}$ & Fixed pie & $\begin{array}{l}\text { Expanding } \\
\text { pie }\end{array}$ \\
\hline $\begin{array}{l}5 . \text { Sense of } \\
\text { victimization }\end{array}$ & $\begin{array}{l}\text { Unbalanced } \\
\text { : One or } \\
\text { both parties } \\
\text { believe } \\
\text { they are the } \\
\text { sole victims }\end{array}$ & $\begin{array}{l}\text { Balanced: } \\
\text { Both parties } \\
\text { realize that } \\
\text { the other } \\
\text { has suffered } \\
\text { from the } \\
\text { conflict }\end{array}$ \\
\hline $\begin{array}{l}\text { 6. Continuity } \\
\text { of interaction }\end{array}$ & $\begin{array}{l}\text { Little or no } \\
\text { expected } \\
\text { future } \\
\text { interaction }\end{array}$ & $\begin{array}{l}\text { Expectation } \\
\text { of a long } \\
\text { term } \\
\text { relationship } \\
\text { characterize } \\
\text { d by much } \\
\text { interaction }\end{array}$ \\
\hline
\end{tabular}

These six dimensions provide a guide for helping mission leadership intervene in conflict among missionaries. By communicating through the most context rich medium available (typically by telephone but perhaps by video conferencing), the manager can help work with each missionary independently to reframe the conflict along each of these dimensions, making it easier to resolve. Once the two parties have reframed the issues along these dimensions, they will be more likely to cooperate (such as by discussing the issues together, listening to each other, and understanding each other's position, all while interacting in a respectful manner), which, in turn, makes a constructive resolution of the conflict more likely. The goal of the manager's intervention is to help both parties reframe the conflict along the various dimensions in order to allow them to come up with a mutually satisfactory outcome to the conflict.

Dimension 1: Involvement of a Third Party

Although the more powerful party in a conflict will naturally resist third party intervention, the presence of a trusted, neutral third party who is even more powerful can have a very calming effect on a conflict and make constructive resolution more likely. Mission leaders can make it clear to both missionaries that they are ready and willing to get involved in spite of the distance and time differences involved. The cost of telephoning is now negligible and, even in the most distant time zones, meetings can be set up in the morning or early evening. Managers need to communicate clearly that they want to get involved. It is all too easy for the parties to think that the issues are too complicated for someone far away to understand. This 
need not be the case. If managers are willing to spend 30-90 minutes in a conversation, they will get a pretty good idea of the problem, at least one party's perspective of the problem. Perhaps the manager will be able to start helping the party reframe the conflict during the first phone call. Perhaps the manager will need to speak to both parties first, to get each one's perspective, and then, on the second phone call, the reframing process can begin. In either case, the involvement of a trusted, neutral third party will have a calming influence and allow the parties to think more rationally about the issues.

Dimension 2: The Nature of the Issue Causing the Conflict

Whenever an issue is framed as a moral issue with an absolute right and wrong position, it is nearly impossible to bridge an impasse. Any compromise would be viewed as a sacrifice of one's integrity and would thus be morally unacceptable. In some cases, a conflict might involve a true moral issue. In this case, a mission leader who intervenes should support the biblically correct side, but such a case is somewhat rare in day-to-day missionary work. To help the parties frame their conflict in terms of something other than moral absolutes, the manager acting as a mediator should remain neutral and objective. Caution must be exercised because each party will tend to frame its position as the morally superior position; even a trivial issue (such as the color of the wall paper) can be framed in moral terms. When conflicts occur over issues that have taken on artificial moral significance for one or both of the parties, a manager must work to help both sides understand each other's point of view and see that the other side's point of view is morally acceptable. The mission leader can help the missionaries understand this by:

- Asking the other missionary to see the situation from the other's point of view.

- Encouraging each missionary to understand why the other missionary believes his or her position is morally acceptable.

- Making sure each party is aware of the possible moral consequences foreseen by the other party.

- Encouraging each missionary to agree that the conflict is not over moral absolutes but over the application of what each missionary agrees is true (e.g., the Bible, the mission's doctrinal statement).

Once each missionary can see the legitimacy of the other missionary's point of view, the problem will be easier to resolve because a change of position by one missionary does not necessarily imply his or her biblical compromise or moral failure.

Dimension 3: Anticipated

Consequences

People tend to magnify the importance of their points of view. In reality, there are very few issues that will necessarily have life-threatening consequences in mission organizations. Even if a person were to die (which occasionally occurs), the organization would carry on its mission and adapt in the necessary ways. Most likely, the issue causing the conflict is much less consequential than a life-and-death concern. If this is the case, mission leaders need to help missionaries put the issue into perspective. It is quite likely that the damage done to the relationship between the two parties is more significant than the possible consequences of making a wrong 
decision about the issue. Managers may help missionaries reframe the issue to make it smaller and less dramatic by:

- Asking what would be the worst consequences to following the other missionary's desired solution, and comparing that to the consequences of sacrificing the relationship.

- Assuring both missionaries that the consequences would probably not be as dramatic as foreseen.

- Urging both missionaries to discuss all possible consequences so that they can be fully aware of each other's point of view.

- Asking each missionary to explain from the other's point of view why the consequences of the other's position would not be so dangerous but would potentially be advantageous.

By reframing the issue as smaller and less consequential, fewer negative emotions will be involved in the discussion by the two parties, making a cooperative solution more likely.

Dimension 4: The Anticipated Resolution of the Outcome

A zero-sum outcome is when a gain (or partial gain) of one party forcibly implies a loss (or partial loss) for the other party. This is also called a fixed-pie perspective (de Dreu, Koole, and Steinel 2000): a larger piece of the pie for one party means a smaller piece for the other. The alternative perspective sees the conflict as having a positive sum outcome. This perspective holds that, by cooperating, a solution can be found that responds optimally to the needs of both parties. This is also known as the expanding pie perspective. The key to arriving at this perspective is to focus on interests, not positions, as described in the classic book Getting to Yes (Fisher et al. 1991). When the two missionaries share this perspective, each missionary seeks to find a new or creative solution that responds to both missionaries' interests so as to produce a win-win solution, rather than focusing on one's initial position and defending it. A mediating manager can help two missionaries have an expanding pie perspective by:

- Working with each missionary to help all the involved parties understand their own underlying interests: what they really want out of the situation at the most fundamental level.

- Helping each missionary to understand the underlying interests of the other missionary.

- $\quad$ Asking both missionaries to prioritize their interests to help them propose solutions that might not be perfect, but are at least better than other possible options.

- $\quad$ Asking each missionary to brainstorm, to come up with possible solutions that would respond to both missionary's interests.

When missionaries can see that at least some of their interests can be met through a creative solution, they will be more willing to explore these options with each other. Helping each missionary to think creatively can be time consuming, but a manager's 
efforts in this area can be particularly rewarding.

Dimension 5: Sense of Victimization If one missionary sees himself or herself as the sole victim of the conflict, the injustice of the situation may cause his or her emotions to rise, and constructive negotiation becomes difficult. In fact, it is highly unlikely that only one person is suffering in a conflict. Both missionaries are likely to see themselves as paying dearly because of the strained relationship. It is likely that they both see the process up to this point as being unfair; each perceives himself or herself as the victim of the behavior of the other. If the mediating manager is aware of the suffering of both parties, this information can be used to show that it is in the interest of both parties to stop hurting each other and begin working on solving the problem together. Realizing that the other has also suffered makes the injustices seem smaller or more balanced, making a party more willing to stop escalating the conflict and begin working towards its resolution. Mediators need to use their power to communicate that enough suffering has occurred and now is the time to begin being constructive.

Dimension 6: Continuity of

Interaction

If a missionary believes that he or she will never have to interact with the other missionary again, there is little motivation to work on repairing the relationship. If the relationship is severely damaged, one missionary might pursue various strategies to make sure that he or she will have no future interaction with the other missionary. This can be accomplished through resigning from the mission or trying to force the other to resign, perhaps by communicating character-assassinating insinuations in order to escalate the conflict to the most damaging level possible. Obviously, mission leaders who want to be faithful to the biblical mandates of making peace (Matt. 5:9, Rom. 14:19) must prevent this from happening. They need to communicate to both parties that conflict resolution is not optional; it must happen no matter how complex and time consuming the process becomes. This becomes easier when the mission leader assures both missionaries that they will have regular contact with each other in the future and that they cannot escape the consequences of unresolved conflict. The missionaries should also be assured that they will be able to work together better and accomplish what they want once the conflict has been resolved and the two parties are reconciled. One technique for moving in this direction would be to ask both parties how they could envision working together in the future if the conflict was resolved and trust was restored. Another possible theme to pursue is that the mission of the organization is bigger than the differences between the individual missionaries; each missionary is morally responsible before God to cooperate and work to restore the relationship in order to demonstrate the power of the gospel (Matt. 5:23-24, 2 Cor. 5:17-20).

\section{Conclusion}

Conflict management among missionaries is a necessary part of the work of mission leaders. Even when the conflict is occurring between missionaries with no trusted mediator in the region, mission leaders can intervene through context rich media, such as the telephone or video conferencing, to help the situation. Intervention through context poor media, such as letters or email, is much less likely to have a positive impact. A mission leader's interaction with each party can lead to reframing the conflict into an opportunity to cooperate and find mutually beneficial solutions. The leader can present information, ask questions, and reassure 
the parties that resolution is possible by addressing topics such as the nature of the issue causing the conflict, the relative importance of the consequences, the potential "expanding pie" nature of the solution, each party's sense of victimization, and the certainty of continued interaction in the missionaries' relationship with each other. It is never easy for a leader to address these issues, but for the sake of accomplishing the organization's mission effectively and fairly, it is essential. 
References Cited

Antonioni, D.

1998 "Relationship Between the Big Five Personality Factors and Conflict Management Styles." International Journal of Conflict Management 9: 336-355.

Argyris, C.

1993 Knowledge for Action: A Guide to Overcoming Barriers to Organizational Change. San Francisco: Josey-Bass Publishers.

Blake, R. R., and J. S. Mouton

1964 The Managerial Grid. Houston, TX: Gulf Publishing Company.

Carnevale, P. J., and D. G. Pruitt

1992 Negotiation and Mediation. Annual Review of Psychology 43: 531582.

Daft, R. L., and R. H. Lengel

1984 "Information Richness: A New Approach to Managerial Behavior and Organization Design." Research in Organizational Behavior 6: 191-233.

Daft, R. L., and R. H. Lengel

1986 "Organizational Information Requirements, Media Richness and Structural Design." Management Science 32: 554-571.

de Dreu, C. K. W., S. L. Koole, and W. Steinel

2000 "Unfixing the Fixed Pie: A Motivated Information-processing Approach to Integrative Negotiation." Journal of Personality and Social Psychology 79: 975-987.

Dennis, A. R., and S. T. Kinney

1998 "Testing Media Richness Theory in the New Media: The Effects of Cues, Feedback, and Task Equivocality." Information Systems Research 9: 256-274.

Deutsch, M.

1973 The Resolution of Conflict: Constructive and Destructive Processes. New Haven, CT: Yale University Press.

Deutsch, M.

2000 "Cooperation and Competition." In M. Deutsch \& P. T. Coleman, eds., The Handbook of Conflict Resolution. Pp. 21-40. San Francisco: Jossey-Bass.

Dirks, K. T., and D. L. Ferrin

2001 "The Role of Trust in Organizational Settings." Organization Science 12: 450-467.

Fisher, R., W. Ury, and B. Patton

1991 Getting to Yes: Negotiating Agreement without Giving In. New York: Penguin Books.

Hay, R., V. Lim, D. Blocher, J. Ketelaar, and S. Hay

2007 Worth Keeping: Global Perspectives on Best Practice in Missionary Retention. Pasadena, CA: William Carey Library.

Johnson, D. W., R. T. Johnson, and D. Tjosvold

2000 "Constructive Controversy." In M. Deutsch and P. T. Coleman, eds., The Handbook of Conflict Resolution. Pp. 65-85. San Francisco: Jossey-Bass. 
Kilmann, R. H., and K. W. Thomas

1977 "Developing a Forced-choice Measure of Conflict-handling Behavior: The 'Mode' Instrument." Educational and Psychological Measurement 37: 309-325.

King, R. C., and W. Xia

1997 "Media Appropriateness: Effects of Experience on Communication Media Choice." Decision Sciences 28: 877-910.

Kraybill, W.

2005 Style Matters: The Kraybill Conflict Response Inventory. Harrisonburg, VA: Riverhouse.

Lewicki, R. L., D. M. Saunders, and B. Barry 2006 Negotiation (5th ed., Vol. 552). New York: McGraw-Hill.

Montoya-Weiss, M. M., A. P. Massey, and M. Song

2001 "Getting It Together: Temporal Coordination and Conflict Management in Global Virtual Teams." Academy of Management Journal 44: 1251-1262.

Naquin, C. E., and G. D. Paulson

2003 "Online Bargaining and Interpersonal Trust." Journal of Applied Psychology 88: 113-120.

Paulson, G. D., and C. E. Naquin

2004 "Establishing Trust via Technology: Long Distance Practices and Pitfalls." International Negotiation 9: 229-244.

Pruitt, D. G., and P. J. Carnevale 1993 Negotiation in Social Conflict. Pacific Grove, CA: Brooks Cole.

Pruitt, D. G., and S. H. Kim 2004 Social Conflict: Escalation, Stalemate, and Settlement (3rd ed.). Boston: McGraw Hill.

Putnam, L. L., and M. Holmer 1992 "Framing, Reframing, and Issue Development." In L. L. Putnam and M. Roloff, eds., Communication and Negotiation. Pp. 128-155. Newbury Park, CA: Sage.

Rahim, M. A.

2001 Managing Conflict in Organizations (3rd ed.). Westport, CT: Quorum Books.

Sandy, S. V., S. K. Boardman, and M. Deutsch

2000 "Personality and Conflict." In M. Deutsch and P. T. Coleman, eds., The Handbook of Conflict Resolution. Pp. 289-315. San Francisco: Jossey Bass.

Schneider, B., H. W. Goldstein, and D. B. Smith 1995 "The ASA Framework: An Update." Personnel Psychology 48: 747-773.

Simons, T. L., and R. S. Peterson

2000 "Task Conflict and Relationship Conflict in Top Management Teams: The Pivotal Role of Intragroup Trust." Journal of Applied Psychology 85: 102-111.

Weingart, L., and K. A. Jehn

2000 "Manage Intra-team Conflict through Collaboration." In E. A. Locke, ed., The Blackwell Handbook of Principles of Organizational Behavior. Pp. 226-238. Malden, MA: Blackwell Publishers.

Wilmot, W. W., and J. L. Hocker

2001 Interpersonal Conflict (6th ed.). Boston: McGraw Hill. 